\title{
$\begin{array}{ll}\text { Research Square } & \text { Preprints are preliminary reports that have not undergone peer review. } \\ \text { They should not be considered conclusive, used to inform clinical practice, }\end{array}$ or referenced by the media as validated information.
}

\section{Torque Mechanical Evaluation for 3D Printed Orthodontic Springs with Different Parameters: Invitro Study}

Ahmed Othman ( $\square$ ahmed.othman@dp-uni.ac.at)

https://orcid.org/0000-0003-1381-7944

\section{Steven Hartman}

Danube Private University https://orcid.org/0000-0003-1298-6607

Dragan Ströbele

Danube Private University

Jassin Arnold

Danube Private University

Constantin von See

Danube Private University

Research article

Keywords: CAD/CAM, 3D printing, Digital Orthodontics, Torque, Springs

Posted Date: April 8th, 2020

DOI: https://doi.org/10.21203/rs.3.rs-19614/v1

License: (c) (1) This work is licensed under a Creative Commons Attribution 4.0 International License.

Read Full License

Version of Record: A version of this preprint was published on March 7th, 2021. See the published version at https://doi.org/10.1186/s12903-021-01473-8. 


\section{Abstract}

Background: The purpose of the presented investigation is to evaluate the resulting torque on loaded 3D printed springs using different coil thickness and length.

Methods: Specimens were designed and printed using the 3D printer MAX (Asiga, Sydney, Australia) with 3D printable, experimental, flexible material (Code:BM2008, GC, Tokyo, Japan). The specimens were divided into three groups according to spring coil design. Control group $(n=18)$, length group $(n=19)$ and thickness group $(n=22)$. Groups were tested using a Sauter Machine for torque calculation (DB, Grindelwald, Switzerland) in conjunction with a universal testing machine (Zwick Z010, Ulm, Germany) for clock-wise and anti-clockwise testing. Statistical analysis was performed using the Steel-Dwass test to compare median values of the three groups in both testing directions $(p<0.001)$.

Results: The highest torque value was determined in the thickness group for both clockwise and anticlockwise testing directions, achieving $44.00 \mathrm{~N} / \mathrm{mm}$ and $39.62 \mathrm{~N} / \mathrm{mm}$ respectively. For the thickness group values ranged from $21.28 \mathrm{~N} / \mathrm{mm}$ anti-clockwise to $44.00 \mathrm{~N} / \mathrm{mm}$ clockwise. The length group ranged from $21.65 \mathrm{~N} / \mathrm{mm}$ to $11.04 \mathrm{~N} / \mathrm{mm}$ in clockwise direction and from $18.04 \mathrm{~N} / \mathrm{mm}$ to $11.38 \mathrm{~N} / \mathrm{mm}$ in counterclockwise testing. The control group ranged from $22.72 \mathrm{~N} / \mathrm{mm}$ to $17.18 \mathrm{~N} / \mathrm{mm}$ in the clock-wise direction while in the anti-clock wise testing it ranged from $21.34 \mathrm{~N} / \mathrm{mm}$ to $16.02 \mathrm{~N} / \mathrm{mm}$.

Conclusions: 3D printed springs are being affected by diameter than length as a design parameter compared to the control group. The thickness group values are statistically significant than the length group $(P<0.001)$. Key words: CAD/CAM, 3D printing, Digital Orthodontics, Torque, Springs.

\section{Background}

The advances in dentistry and malocclusion corrections for development of a healthy occlusion have led to an increased demand of orthodontic treatment. Malocclusion can vary depending on certain factors including the dental angle classification, skeletal classification and genetic factors ${ }^{(1-3)}$. Orthodontic movements vary depending on the degree of malocclusion, other biological factors such as age and suspected treatment planning ${ }^{(2-5)}$.

The spring design and materials used can greatly affect the amount of forces loaded ${ }^{(6,7)}$. Different spring designs provide different types of movements ${ }^{(8)}$.

Brackets and wires now can be fabricated by CAD/CAM technology on a virtual setup designed before commencing with the treatment. Thus, the final product is a precise duplicate of pre-treatment digital setup greatly diminishing chances for error ${ }^{(9)}$. Digital orthodontic treatment is being considered for clinical usage as CAD/CAM technology is nowadays being directly involved in dentistry ${ }^{(10-12)}$. Digital fabrication of fixed functional orthodontic appliances is clinically proven for its successful results ${ }^{(13)}$. However, digital designing and printing of orthodontic springs is not until now considered nor tested. The 
necessary requirements are influenced by the individual design of each spring and the ability to attach and support the spring to the tooth surface.

The 3D printing resin material for orthodontic springs is recently developed with neither data nor studies available for its efficiency.

Accordingly, the aim of the present investigation was to mechanically evaluate the torque of the digitally designed and 3D printed orthodontic springs invitro by having differently designed orthodontic spring groups prior to clinical application.

\section{Methods}

In the present investigation, spring specimens were 3D printed using MAX (Asiga, Sydney, Australia) with DLP (digital light processing) technology via the experimental flexible printable material (Code:BM2008, GC, Tokyo, Japan). The specimens were designed by the computer aided program Autodesk Netfabb (San Rafael, CA, USA). The post processing of the specimens was performed by GC-Europe and according to the manufacturer's instructions. Unheated ultrasonic reusable isopropanol solution with concentration of $96 \%$ was manipulated to clean the specimens for 2 minutes followed by 2 more minutes of a clean isopropanol bath with the same concentration.

The specimens were withdrawn from the solution bath and dried with compressed air in-between the two cleaning cycles. Surface polymerization was done using Labolight DUO (GC, Tokyo, Japan) with double wavelength LED technology in a range of $380 \mathrm{~nm}-510 \mathrm{~nm}$ with spectrum range peaks of $465 \mathrm{~nm}$ $485 \mathrm{~nm}$ (12 Blue LED's) and $390 \mathrm{~nm}-400 \mathrm{~nm}$ (3 Violet LED's). Two periods of 3-minute durations each were applied, and the samples were turned for curing from both sides. After post curing, carbide bur and nipper were used to remove supports.

After eliminating all specimens' printable supports, the specimens were divided into three different groups according to their different design parameters, control group $(n=18)$, length group $(n=19)$ and thickness group $(n=22)$ (Table 1 \& Figs. $1-3)$

\begin{tabular}{|llll|}
\hline Group & Control group & Length group & Diameter group \\
\hline Specimens & 18 specimens & 19 specimens & 22 specimens \\
\hline Feature & Two identical springs & different coil numbers & different coil radius \\
\cline { 3 - 4 } & & $\left(\mathrm{n}_{1}=4, \mathrm{n}_{2}=6\right)$ & $(\mathrm{Dr}=0.15 \mathrm{~mm})$ \\
\cline { 3 - 4 } & & &
\end{tabular}

Table.1: Overview of the group classification

The control group was characterized by two in design identical springs, while the length group was characterized by two springs with a difference in coil-number $\left(n_{1}=4, n_{2}=6\right)$ and the diameter group was 
defined by two coils with different radius $(\Delta r=0.15 \mathrm{~mm})$. A reference key was designed using Autodesk Netfabb (San Rafael, CA, USA) and printed with the Varseowax Model material using Varseo S 3D printer (BEGO, Bremen, Germany), which acted as a spring's attachment to the torque measuring device (Sauter DB 0.5-4, Grindelwald, Switzerland). In order to assure pointed force exertion upon the springs base, a C shaped 3D printed key was loaded into the universal testing machine (Z010 Zwick/Roell, Ulm, Germany). The $C$ shaped key was designed using Autodesk Netfabb (San Rafael, CA, USA) and printed with the Varseowax Model material using Varseo S 3D printer (BEGO, Bremen, Germany). (Figure.4)

The specimens attached to the torque device via the reference key were loaded in the universal testing machine and measured in clockwise and anti-clockwise direction for five cycles each (Figure.4). All results of both clockwise and counter clockwise force exertion was recorded in $\mathrm{N}$ (Newton) and the maximum values for each specimen were recorded.

\section{Descriptive Analysis}

Results were divided in the three groups: control, length and thickness with clockwise as well as counter clockwise testing for each of the three groups. Statistical analysis was performed using Steel-Dwass test to compare median values of the three groups in both testing direction $(p<0.001)$.

\section{Results}

The compiled data that was gathered from the measurements was to be compared and analyzed for statistical analysis between the groups. The values of both clockwise and counter clock-wise data sets were calculated separately (Fig. 5,6).

The statistical analysis showed significant difference between the three groups of springs $(p<0.001)$. Clockwise and counter-clock wise mechanical testing both proved significant differences for the diameter group $(p<0.001)$. The highest measured values found for the diameter group was $44.00 \mathrm{~N} / \mathrm{mm}$. The lowest scores noted was within the length group $11.04 \mathrm{~N} / \mathrm{mm}$.

The length and diameter groups were statistically significantly different. For the control group, the maximum value was $22.72 \mathrm{~N} / \mathrm{mm}$. For the length group, the maximum value was $21.65 \mathrm{~N} / \mathrm{mm}$, while for the diameter group the maximum value was $44 \mathrm{~N} / \mathrm{mm}$. The torque range for the control group ranged from $22.71 \mathrm{~N} / \mathrm{mm}$ to $17.18 \mathrm{~N} / \mathrm{mm}$ and in the length group the values ranged from $21.65 \mathrm{~N} / \mathrm{mm}$ to $11.04 \mathrm{~N} / \mathrm{mm}$. The diameter group torque ranged from $44 \mathrm{~N} / \mathrm{mm}$ to $21.28 \mathrm{~N} / \mathrm{mm}$. The diameter group displays a significant difference to the control group in both clockwise and counter clock-wise distributions $(p<0.001)$. Control and length groups displayed a similar significance difference as the diameter group did with a clockwise difference of $(p<0.007)$ and counter clockwise difference of $(p<$ 0.001). 
A non-parametric comparison test for all three groups using the Steel-Dwass method was utilized. The non-parametric comparison of all three groups for both testing directions, clock and counter clockwise, calculated the median instead of the mean.

The Steel-Dwass test then calculated the diameter which would be significant for both clock and counter clockwise when compared to either control and length groups $(p<0.001)$. However, when the groups control and length were compared, the significant value for clockwise was $(p<0.007)$ and $(p<0.001)$ for the counter clockwise.

\section{Discussion}

The aim of the present investigation was to mechanically evaluate the torque resulted from the digitally designed and 3D printed orthodontic springs with different design parameters by mechanical loading in clock-wise and counter-clockwise direction. It was proven, that the thickness group had a highly significant torque value in clock wise than in counter-clockwise direction.

For all test groups, springs were tested in both clock-wise and counter-clock wise direction to ensure torque withstanding in both directions using the 3D printed orthodontic material.

All groups compared in clockwise as well as counter-clockwise have a significant difference $(p<0.05)$

Regarding materials and methods, all specimens were 3D designed by (Auto desk, Netfabb, San Rafael, CA, USA) and 3D printed via (Asiga Max, Sydney, Australia) to have all orthodontic springs of the mentioned 3 groups.

The study protocol followed the manufacturer's instructions for post processing. This ensured uniform results. A 3D printed reference key for holding the springs to the torque device (Sauter DB 0.5-4, Grindelwald, Switzerland) was constructed, and using 3D printed C shaped key attached to the Z010 Zwick/Roell machine (Ulm, Germany) for one-point force application mechanical testing of the springs. The machine speed starting position with $50 \mathrm{~mm} / \mathrm{min}$ and 5 seconds holding time in-between the clockwise and counter clock wise directions for torque measuring was applied. Furthermore, torque testing was used to find out whether the designed springs can develop sufficient deflection and compression processes to evaluate the tooth movement possibility with a 3D printed spring. Contrary to the current metallic springs, where a simple compression process results in acceptable forces for orthodontic usage ${ }^{(6)}$.

Printed springs may need a combination of deflection and compression processes to develop sufficient forces to enable tooth movement possibility with a 3D printed spring. However even with increased effort, torque and force still aid orthodontic treatment ${ }^{(14,15)}$. Clinical use cannot be simulated entirely invitro with standardized tests, but it's possible to find material-specific properties invitro ${ }^{(16)}$. In the present investigation, significant difference between the groups for 3D printed springs was found. This study is in line with Chudasama et al who determined that wire size has a direct effect on the amount of exerted 
force ${ }^{(17)}$. Further studies and experiments should be undertaken to investigate this effect in depth. As a limitation, the amount of friction between the springs and the reference key was not measured because of the inability to determine this amount of friction precisely.

A study conducted by Ubirajara et al. showed that spring parameters are greatly influencing the mechanical effect ${ }^{(6)}$. It is difficult to compare the effect of the printed springs to the laboratory constructed springs because of the material used and the construction method. This is due to the fact that every study is performed with different devices as well as with different operators. For this reason, the absolute data for torque and the obtained values can be compared only inside the same study. In a study conducted by Davidović et al ${ }^{(18)}$, closed coil springs made of nickel titanium material were compared to elastic chains. A similar approach for three dimensionally printed springs could be undertaken to determine their efficiency when paired against other materials on the orthodontic field. Another study, performed by Barwart et al ${ }^{(19)}$ tested the super elasticity of nickel titanium springs under different temperatures. Such a study would prove invaluable for understanding how the $3 \mathrm{~d}$ printed material endures in vivo, as oral temperature fluctuations occur, for instance during meals ${ }^{(19)}$. A third study by Nattrass et al explored the environmental factors that influence both elastomeric chain and nickel titanium springs ${ }^{(20)}$. Another worthwhile study that should be conducted with three dimensionally printed springs. The resistance of this new orthodontic material for springs should be further investigated before clinical consideration. More detailed studies are required, especially the chemical polymerization process within the printable resin needs further investigation. This study is preliminary a feasibility testing of the 3D printed material in which the parameters should be evaluated in depth before any clinical relevance.

\section{Conclusion}

The findings showed a higher torque value for the diameter group compared to the control group and a clear increase of value in clockwise direction for diameter group with mechanical testing. The length group did not show a significant difference between the two testing directions.

\section{Declarations}

Ethics approval and consent to participate: Not applicable Consent for publication: Not applicable Availability of data and materials: The datasets used and/or analysed during the current study are available from the corresponding author on reasonable request. Competing interests: The authors declare that they have no competing interests. Funding: This research project received no monetary funding.

Authors' contributions: A.O and C.V were responsible for study conception and design also the major revision. S.H and D.S were responsible for study analysis and interpretation of data. J.A was responsible for drafting of the manuscript. All authors read and approved the final manuscript. 
Acknowledgements: Univ. Prof. Dr. PhDr. Wilhelm Frank MLS for statistical review of Data gathered.

\section{References}

1. Čelar A, Tafaj E, Graf A, Lettner S. Association of anterior and posterior occlusal planes with different Angle and skeletal classes in permanent dentitions. Journal of Orofacial Orthopedics/Fortschritte der Kieferorthopadie. 2018;79(4):267-76.

2. Little RM, Wallen TR. Chapter 8: Orthodontics. In: Review of Basic Science \& Clinical Dentistry: Clinical Dentistry. Vol 2. People's Medical Publishing House USA Ltd (PMPH); 2003:230-247.

3. Sharma K, Batra P, Sonar S, Srivastava A, Raghavan S. Periodontically accelerated orthodontic tooth movement: A narrative review. Journal of Indian Society of Periodontology. 2019;(1):5.

4. Santos RL dos, de Oliveira Ruellas AC. Dentofacial characteristics of patients with Angle Class I and Class II malocclusions. Dental Press Journal of Orthodontics. 2012;17(2):46-48.

5. Aslam K, Nadmir R, Rizwan S. Prevalence of Angles Malocclusion According to Age Groups and Gender. Pakistan Oral Dental Journal. 2014;34(2):362-5.

6. Ubirajara Pires B, Evangelista de Souza R, Vedovello Filho M, Degan VV. Bento dos Santos JC, Malanconi Tubel CA. Force degradation of different elastomeric chains and nickel titanium closed springs. Brazilian Journal of Oral Sciences. 2011;10(3):167-70.

7. Bourauel C, Drescher D, Ebling J, Broome D, Kanarachos A. Superelastic nickel titanium alloy retraction springs-an experimental investigation of force systems. Eur J Orthod. 1997;19(5):491500.

8. Ferreira MA, Assumpção R, Luersen MA, Borges PC. Mechanical behaviour of a prototype orthodontic retraction spring: a numerical-experimental study. Eur J Orthod. 2013;35(4):414-20.

9. Alharbi N, Wismeijer D, Osman RB. Additive Manufacturing Techniques in Prosthodontics: Where Do We Currently Stand? A Critical Review. International Journal of Prosthodontics. 2017;30(5):474-84.

10. Bührer. Samra AP, Morais E, Mazur RF, Vieira SR. Nunes Rached R. CAD/CAM in dentistry - a critical review. Revista Odonto Ciencia. 2016;31(3):140-4.

11. bin Irfan U, Aslam K. Rizwan Nadim. A Review on Cad Cam in Dentistry. Journal of the Pakistan Dental Association. 2015;24(3):112-6.

12. Patel N, Contemporary Dental CAD/CAM. Modern Chairside/Lab Applications and the Future of Computerized Dentistry. Compendium of Continuing Education in Dentistry (15488578). 2014;35(10):739-46.

13. Kwon S-Y, Kim Y, Ahn H-W, Kim K-B, Chung K-R. Seong-Hun Kim (Sunny). Computer-Aided Designing and Manufacturing of Lingual Fixed Orthodontic Appliance Using 2D/3D Registration Software and Rapid Prototyping. International Journal of Dentistry. January 2014:1-8.

14. Schwindling F-P. Kraft und Raum - unsere orthodontischen Medikamente Teil 1 - Kraft. (German). Kieferorthopaedie: die Zeitschrift für die Praxis. 2017;31(2):175-86.

15. Schwindling F-P. Kraft und Raum - unsere orthodontischen Medikamente Teil 2: Drehmoment. (German). Kieferorthopaedie: die Zeitschrift für die Praxis. 2017;31(3):275-83. 
16. UmaMaheswari B, Geetha PK, Nagaraj KR, Shwetha K. Comparative Analysis Of The Flexural Strength Of Conventional Polymethyl Methacrylate Resin, High Impact Resin And Glass Fiber Reinforced Resin - An Invitro Study. Indian Journal of Dental Sciences. 2013;5(4):77-9.

17. Chudasama D, Jerrold L. SPRINGS into Action Orthodontic Products. 2009;16(2):54-6.

18. Davidović MU, Savić MA, Arbutina A. Examination of postextraction space closure speed using elastic chains and NiTi closed coil springs. Serbian Dental Journal / Stomatološki Glasnik Srbije. 2018;65(4):179-186.

19. Barwart $O$, Rollinger J, Burger A. An evaluation of the transition temperature range of super-elastic orthodontic NiTi springs using differential scanning calorimetry. Eur J Orthod. 1999;21(5):497.

20. Nattrass C, Ireland A, Sherriff M. The effect of environmental factors on elastomeric chain and nickel titanium coil springs. Eur J Orthod. 1998;20(2):169.

\section{Figures}




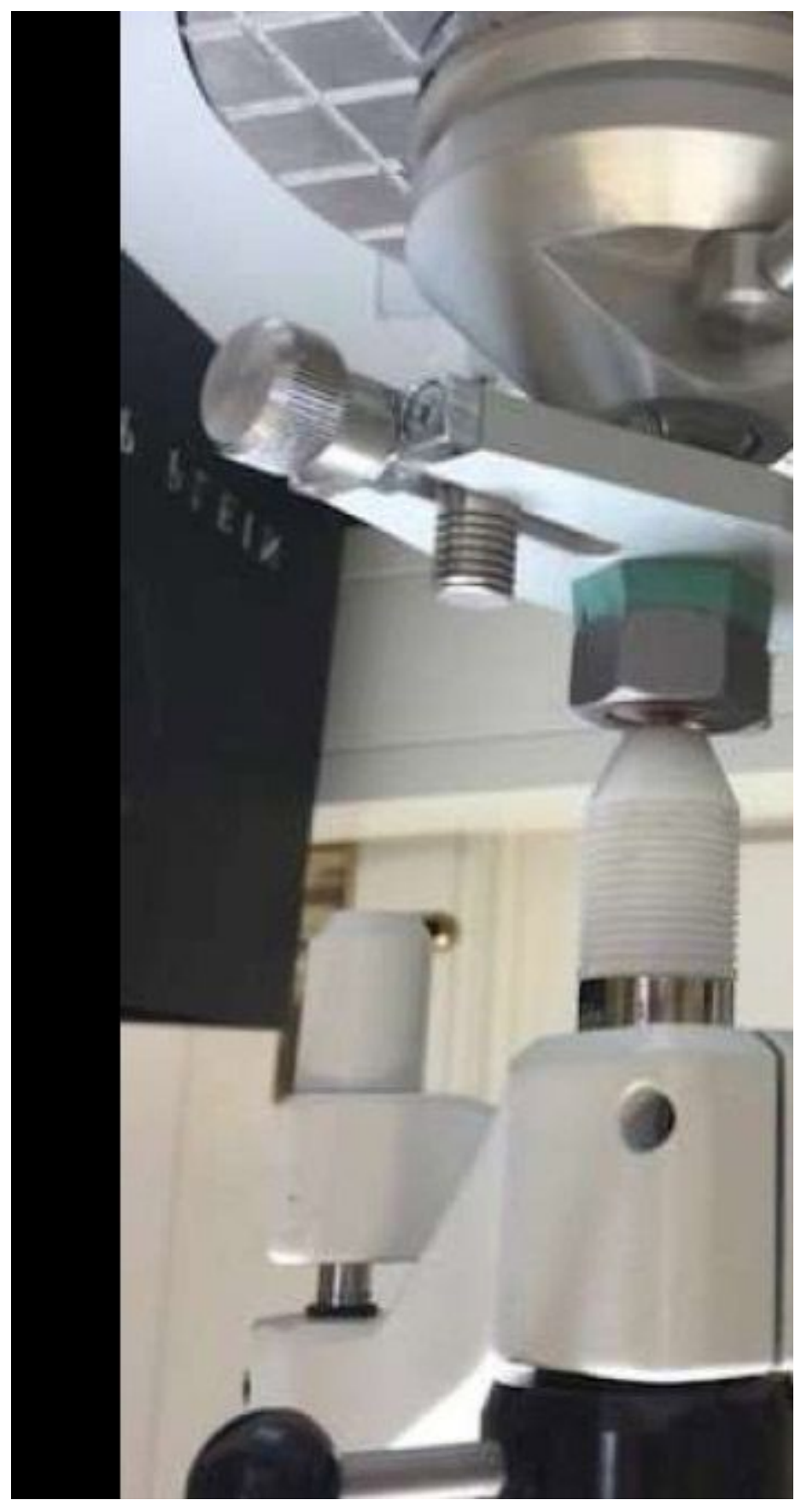

Figure 1

Control Group 


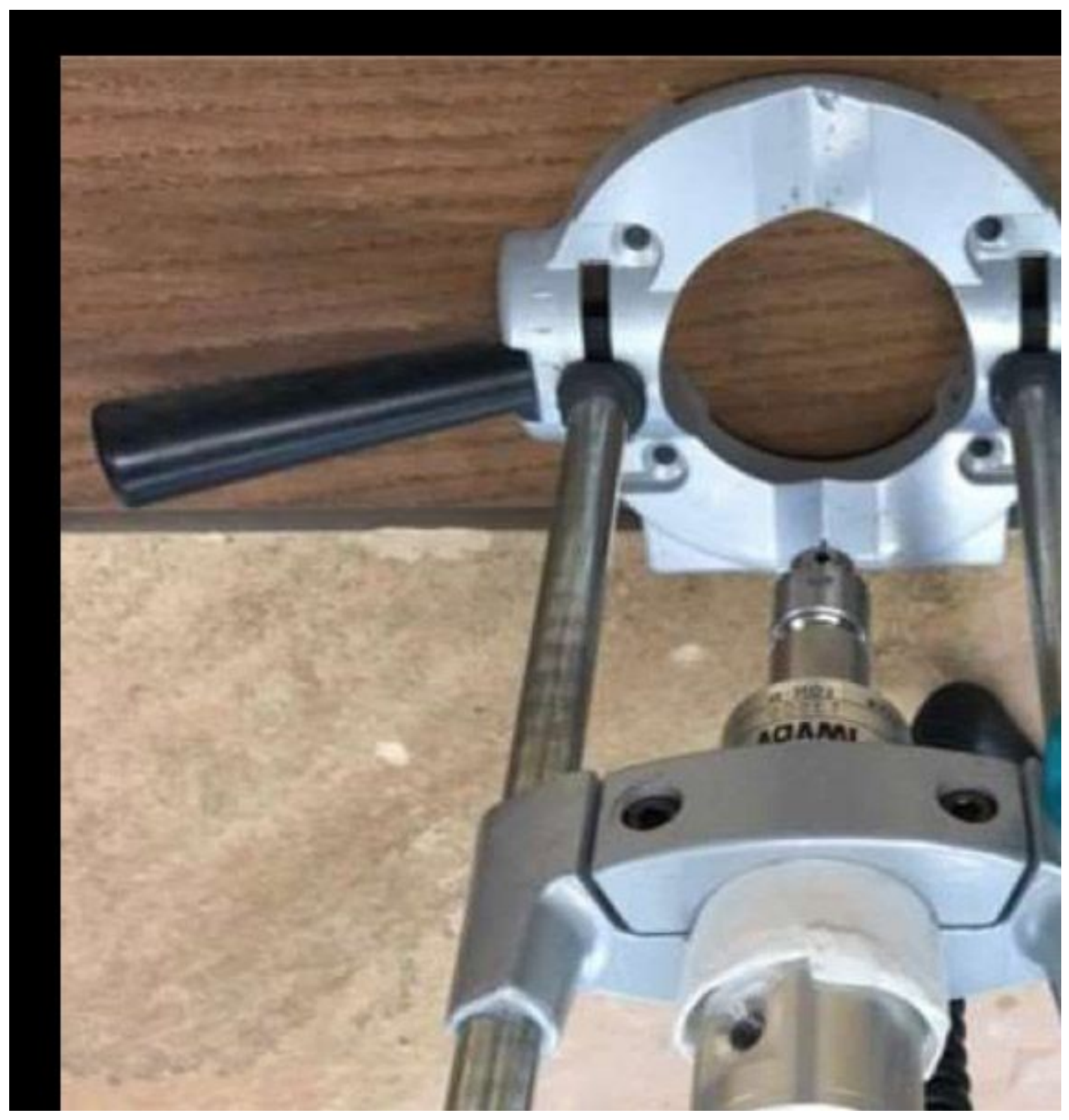

Figure 2

Length Group 

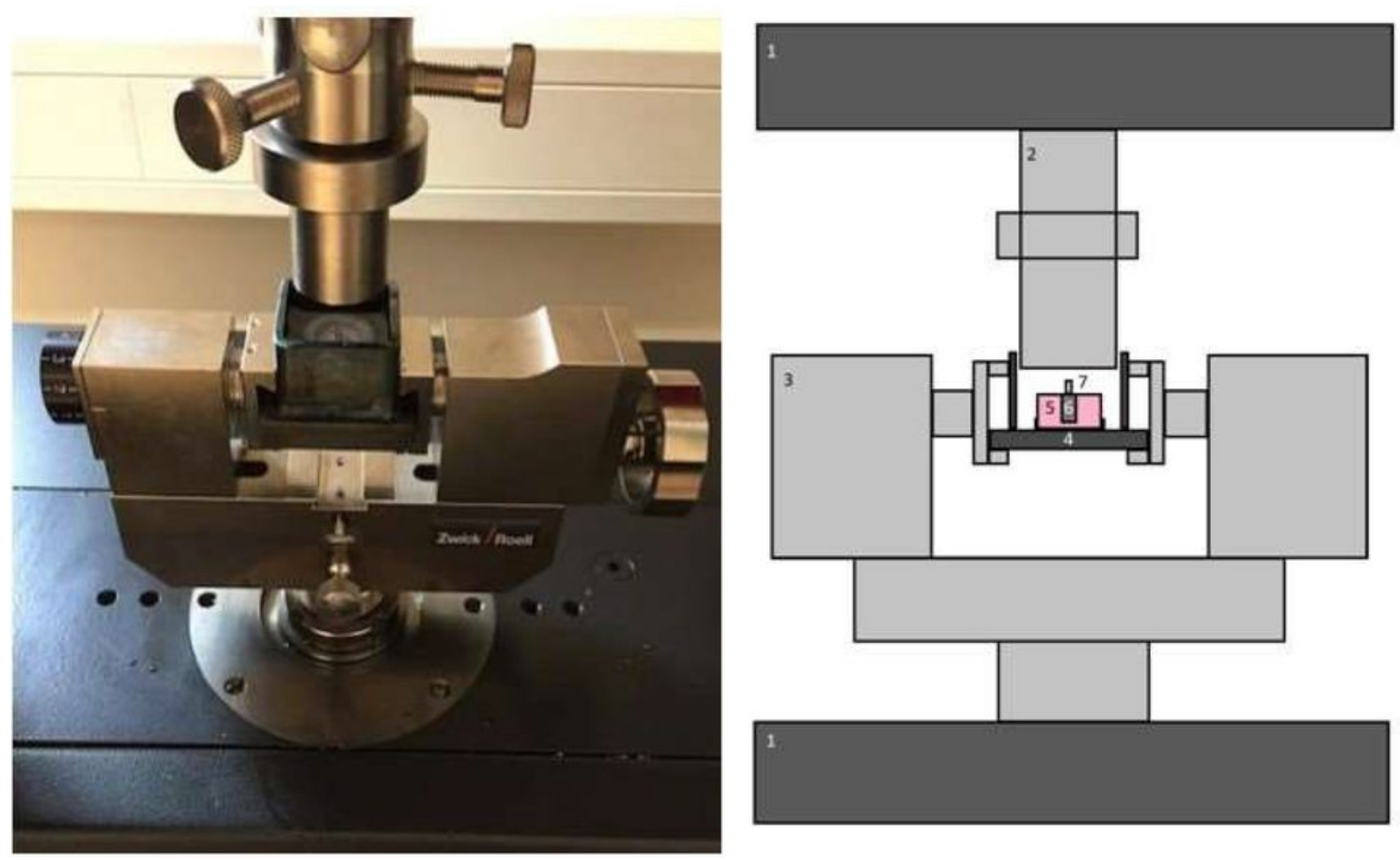

Figure 3

Diameter Group

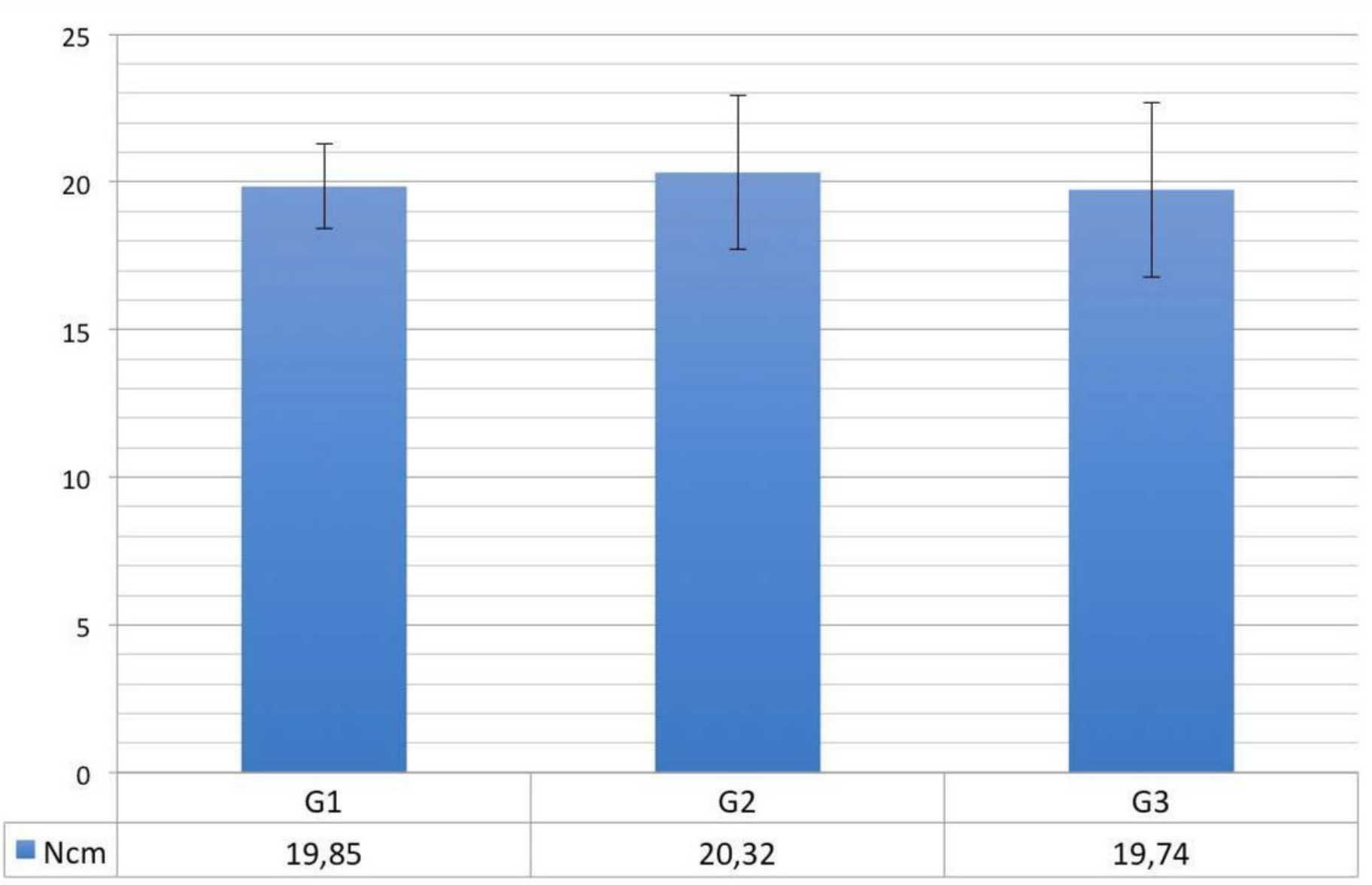

Figure 4 
Testing process (Seen above, the $\mathrm{C}$ shaped construct and the reference key locking a spring in place for testing with the Z010 Zwick/Roell (Ulm, Germany) upon initiation the $\mathrm{C}$ shaped will be shifted up and down so that each end delivers forces onto the spring which are then recorded by torque device (Sauter DB $0.5-4$, Grindelwald, Switzerland) this process is repeated five times total in both directions for every spring tested)

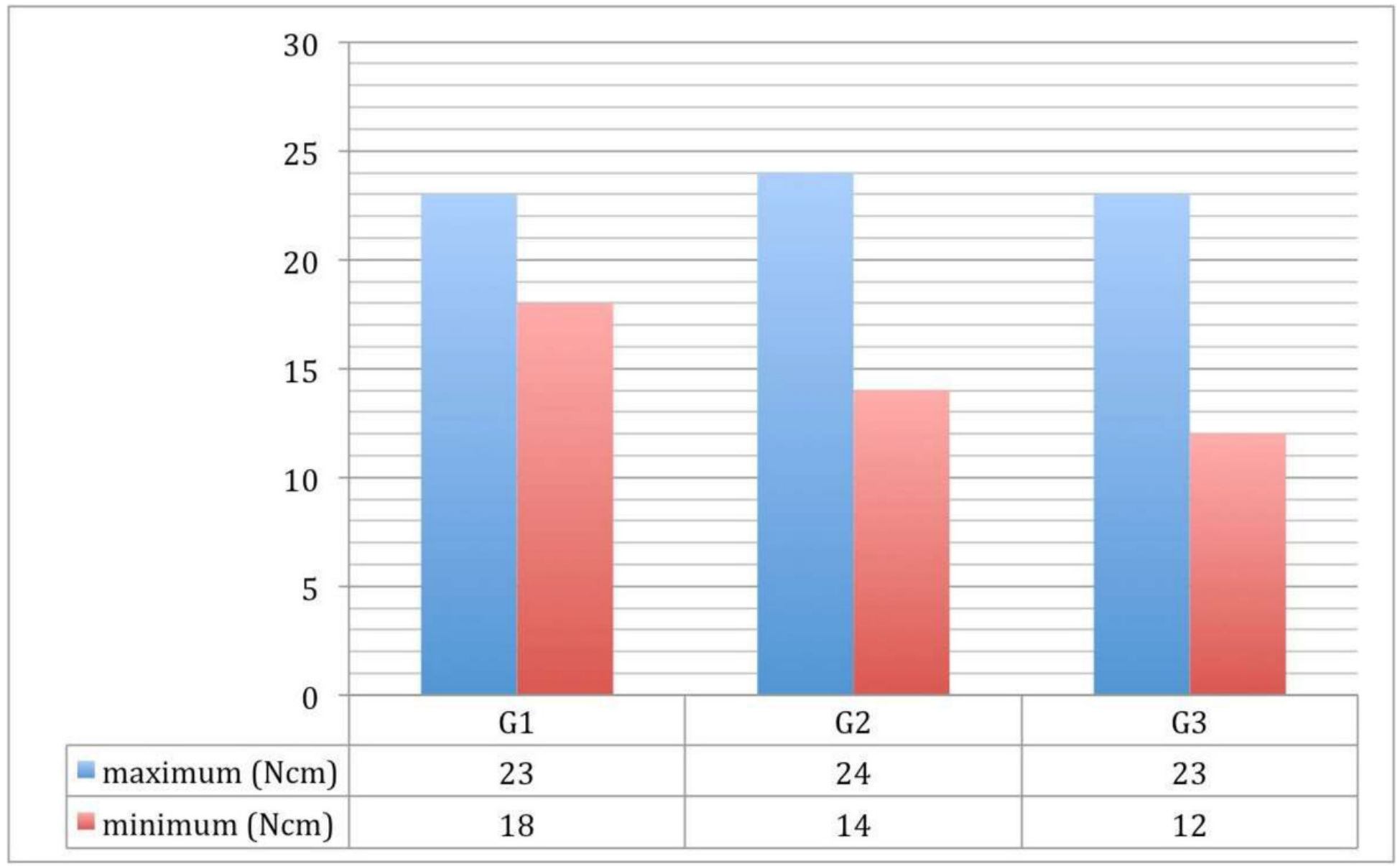

Figure 5

Distribution of clockwise data set 


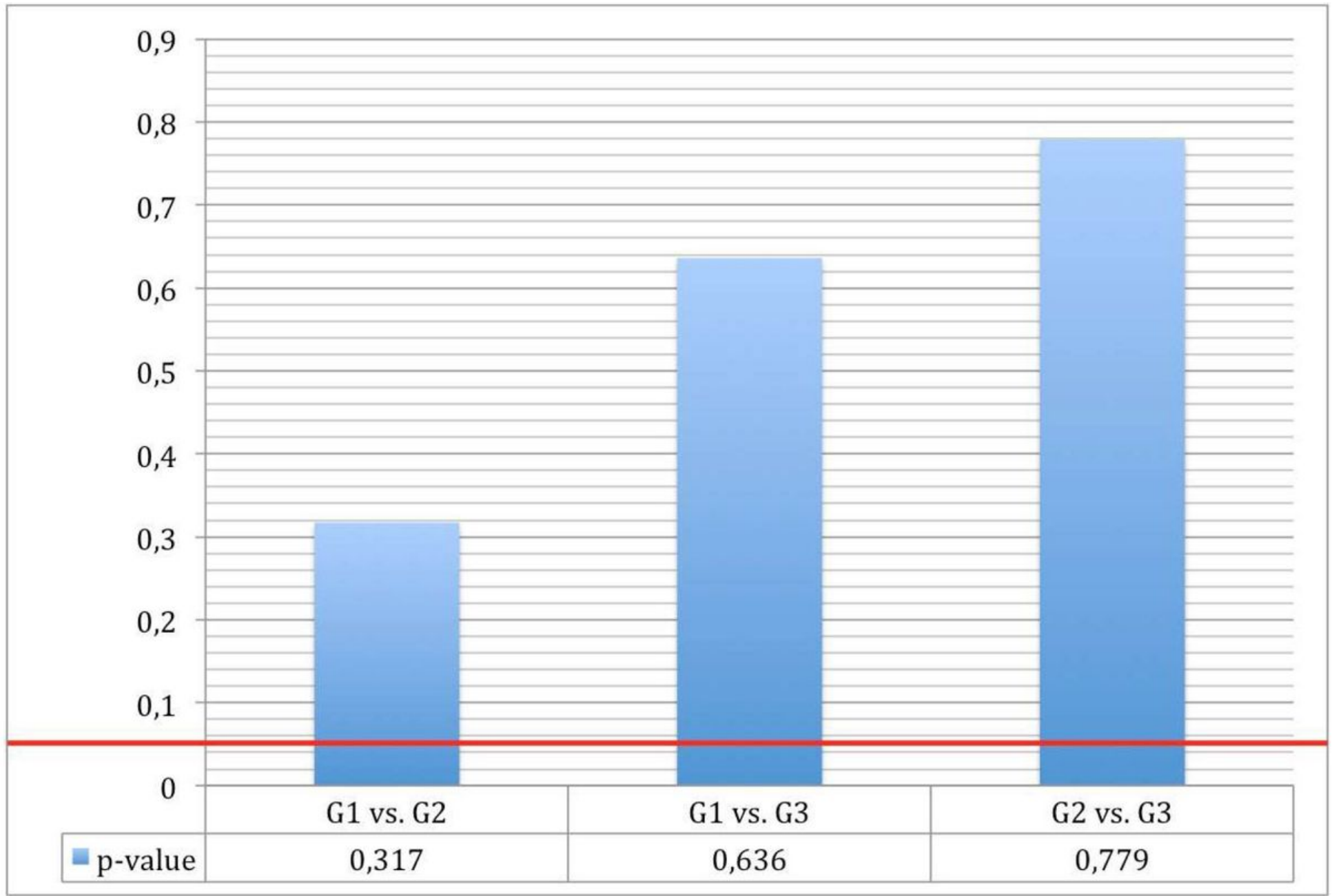

Figure 6

Distribution of counter clockwise data set 